\title{
ERotismo FEMENINO EN (DES) ENCUENTROS (DES) ESPERADOS DE Andrea Maturana*
}

Fecha de Recepción: 13 de febrero de 2013

Fecha de aprobación: 17 de mayo de 2013

\section{Resumen}

La literatura erótica en Chile desde una autoría femenina se instala tímidamente en la década de los noventa con la obra: (Des) encuentros (des) esperados de la escritora chilena Andrea Maturana. Este artículo pretende demostrar que en esta obra literaria se revierte el prototipo sexual asignado a la mujer hasta el momento.

La investigación procura indagar en el comportamiento de los personajes femeninos en el ámbito erótico, identificar una visión de mundo a través de esas acciones, analizar las voces narrativas e ilustrar el panorama histórico social de la década, el cual tiene una alta incidencia en la creación de los personajes, debido a los cambios que se advierten con la Transición.

Palabras claves: literatura erótica, Chile, prototipo sexual, mujer, Transición

\footnotetext{
* Artículo de investigación científica, enmarcado en la investigación sobre el erotismo en la obra de Andrea Maturana llevado a cabo en la Universidad de Talca.
}

Citar: Barraza Pizarro, L. (Julio-Diciembre de 2013). Erotismo femenino en (Des) encuentros (Des)esperados de Andrea Maturana. La Palabra(23), 63-76.

\section{Lilian Barraza Pizarro}

Universidad de Talca, Chile. libebali@gmail.com

Licenciado en Educación con mención en Español, Universidad de Concepción, Chile. Magister en Educación de las Humanidades, Literatura y Artes, Universidad de Talca, Chile. 


\title{
FeMENINE EROTICS IN (DES) ENCUENTROS (DES) ESPERADOS [DESPERATE DISENCOUNTERS] BY ANDREA Maturana
}

\begin{abstract}
Erotic literature in Chile by female authorship emerged quietly in the decade of the 1990s with the work (Des) encuentros (des) esperados [Desperate (Dis) Encounters] by the Chilean author Andrea Maturana. This article aims at demonstrating that the sexual prototype so far assigned to women is reversed in this literary work. This study intends to examine the behaviour of the female characters in the erotic sphere and identify their worldview through these actions. It also analyses their narrative voices and illustrates the social / historical context of the decade, which has great influence in the creation of the characters, due to the changes manifested in the Transition.
\end{abstract}

Key words: erotic literature, Chile, sexual prototype, transition.

\section{ÉROTISME FÉMININ DANS (DES) ENCUENTROS (DES) ESPERADOS [DES (DÉS-) RENCONTRES (DÉS) ESPÉRÉES] D’ANDREA MATURANA}

\section{Résumé}

La littérature érotique au Chili dès une création féminine, s'installe d'une manière timide dans les années quatre-vingt-dix avec l'œuvre (Dés-) rencontres (dés)espérés de l'écrivaine chilienne Andrea Maturana. Cet article prétend démontrer que dans cette œuvre littéraire-là, on détourne le prototype sexuel attribué à la femme jusqu’à ce moment-là.

La recherche essaye d'enquêter sur le comportement des personnages féminins dans l'ambiance érotique ; d'identifier une vision du monde à travers ces actions-là ; d'analyser les voix narratives et d'illustrer le panorama historique social de la décennie, celui qui a une grande incidence dans la création des personnages, dû aux changements qui sont constatés avec la Transition.

Most clés: Littérature érotique, Chili, prototype sexuel, femme, transition 


\section{Introducción}

\section{(Des)encuentros (des)espe-} rados es una sutil deflagración de pasión, una llamarada que enciende fuegos silentes guardados por siglos de subordinación y que en estos relatos se abre sigilosamente hacia un espacio no explorado, sin descripciones ramplonas del acto sexual, un espacio que se recrea desde el propio placer femenino.

El erotismo ha sido un tema muy difamado, hablado sólo a través de disfemismos. Es tiempo de valorarlo sobre una base de respeto e integrarlo a nuestras historias personales y sociales dentro de parámetros de normalidad. Surge así, la necesidad de demostrar que las voces narrativas femeninas logran con ahínco este cometido, pues no mancillan el concepto ni a los sujetos que gozan de éste, desestructurando los estereotipos amorosos que se tenían hasta entonces.

El Trabajo que se presenta a continuación parte de investigar ensayos teóricos referidos al erotismo y apreciar el comportamiento que se le ha asignado a la mujer en esta materia. Debido al año de publicación del libro en estudio, también se hace un pequeño análisis de la realidad chilena de la década de los noventa en cuanto a contexto histórico social; se habla de la narrativa del mismo periodo y de la línea o proyecto creativo de la autora Andrea
Maturana. Su prosa se ha estudiado exiguamente en Chile, sin embargo más abundante ha sido la investigación en Universidades extranjeras, tal es el caso de la Universidad de Memphis en donde Crosby analiza $\mathrm{La}$ traición paterna y el incesto en su novela El daño. En el caso de nuestra obra en particular, Maíz-Peña titula su investigación: Los apetitos de la ansiedad: cuerpo - texto; Mateo del Pino: Cuando lo que (des)une no es el amor sino el espanto y Villalobos; (Des)encuentros (des) esperados de Andrea Maturana. La ciudad que vigila. Pero ni el espanto, ni la ansiedad, ni la ciudad que vigila son los que convocan mi estudio. (Des) encuentros (des)esperados da un gran salto en la narrativa femenina chilena al abordar el tema erótico, considerando los signos de poder establecidos en un país con diecisiete años de dictadura que había censurado abiertamente el arte en todas sus expresiones. Liberar la voz narrativa femenina ya en los noventa era "clandestino", más aún lo era exhibir el erotismo a través de personajes femeninos cuyas acciones manifestaban normalidad y goce.

\section{Rol sexual de la mujer a lo largo del tiempo}

Aristóteles, citado por Foucault en Historia de la sexualidad (1993b, p.24), veía en la mujer un elemento sexual pasivo. Mientras ella proveía la materia del embrión, el hombre le infundía a esta materia forma y movimiento. En su libro Política (Libro I), el pensador griego expresa que el varón atesoraba valores heroicos en la guerra, se caracterizaba por un lenguaje transmisor de conocimientos y utilización de sólidos argumentos, a diferencia de la mujer, cuyo valor consistía en obedecer y utilizaba el lenguaje sólo para opinar. De ahí, que frente a esta superioridad genérica, se educara sexualmente al varón por una cuestión de poder y dominación que también adquiere el hombre en el acto de la penetración (s.p.).

Artemidoro, en su onirocrítica: Clave de los sueños, según Foucault (1992), daba especial relevancia a los sueños eróticos. En este texto se habla mayoritariamente del sueño de los hombres, aun cuando no descarta que las mujeres sueñen. Las mujeres son el objeto de deseo en el inconsciente del hombre y éste puede evocartres tipos de personajes: la esposa, la amante y la prostituta. La interpretación que se hacía de los sueños era fundamental para "gobernar la propia existencia" (p. 29). En el pensamiento de los filósofos y médicos griegos, Foucault percibe una gran austeridad en el goce sexual.

Para Georges Bataille (s.f.), la relación entre hombre $\mathrm{y}$ mujer era de sacrificador y de víctima, respectivamente. "La mujer, en manos de quien la acomete, está desposeída de 
su ser. Pierde con el pudor, esa barrera sólida que, separándola del otro, la hacía impenetrable; bruscamente (...) se abre a la violencia impersonal que la desborda desde fuera" (p. 67). También aclara que el objeto de deseo es siempre la mujer, la que no es más deseable que los hombres, pero "ellas se proponen al deseo" (p. 99).

Según este autor, los sujetos del deseo: hombre en un rol activo y mujer, en rol pasivo, llegan a la destrucción de su ser. La mujer es disuelta como ser constituido, mientras que el hombre se disuelve para volver a construirse. Sumado a esto, la intención del sujeto de transgredir lo prohibido conlleva un estado de angustia, convirtiendo la emocionalidad erótica en una dicotomía entre deseo y pavor, placer y angustia.

Los pensadores franceses de la ilustración imbuidos en el saber y el raciocinio, también se refirieron al tema. Jean Jaques Rousseau, en Emilio o De la educación (trad.2000), establece diferencias entre hombre y mujer al momento de la reproducción: el varón es el agente masculino, debe ser fuerte y activo; la mujer, en cambio, debe permanecer como ser pasivo y débil que está hecho para agradar y ser subyugado.

Por su parte, los positivistas en el siglo XIX generaron un estudio biológico respecto a los comportamientos sexuales y características de gé-

nero. Augusto Comte, citado por Guerra (2006), escribió en 1839 Cours de philosophie positive, "demostrando que la mujer permanece en un estado infantil perpetuo y que, de manera similar a aquella observada en los animales inferiores, ella posee una preponderancia de sus facultades afectivas" (p. 67). En su óptica, Comte veía a la mujer como el "ángel del hogar" al cual debía educársele para que orientara moralmente la educación del hombre.

La introducción de la teoría del Psicoanálisis de Sigmund Freud impactó totalmente a fines del siglo XIX, dentro de sus preocupaciones estuvo la histeria asignada a la mujer por naturaleza y por la cual también era encerrada en la casa, bajo vigilancia del varón y de los médicos. Cito a Foucault (1993a):

\begin{abstract}
Histerización del cuerpo de la mujer: triple proceso según el cual el cuerpo de la mujer fue analizado - calificado y descalificado - como cuerpo integralmente saturado de sexualidad (...) con su imagen negativa que es la "mujer nerviosa", constituye la forma más visible de esta hostilización. (p. 127)
\end{abstract}

Toda esta vigilancia frente al tema sexual de parte de psiquiatras, padres e instituciones pedagógicas, conformaron un sistema de poder que pretendía regular otro de integración social y de reproducción. Pero, según Foucault, al cabo del tiempo, más que disminuir el "problema" por la ansiedad sexual y el placer, lo sobresaturó. (p.61).

\section{Contexto social en la década de los noventa en Chile}

El 11 de septiembre de 1973 Augusto Pinochet derrocó a Salvador Allende a través de un golpe de estado. Desde entonces se vivieron diecisiete años de dictadura en Chile. En la década de los noventa, tras el plebiscito en que se da por ganador al "No", surge el primer gobierno elegido democráticamente, cuyo mandatario fue don Patricio Aylwin. Este fue un gobierno de transición, pues Pinochet siguió como Jefe de Ejército hasta 1998 y gracias a la Constitución de 1980, más adelante continuó como Senador vitalicio, adhiriéndose a la Ley de amnistía, lo que le dio impunidad en Chile hasta el día de su muerte. A pesar de esto, el 9 de febrero de 1991, la Comisión Nacional de Verdad y Reconciliación entregaba el tan polémico Informe Rettig, sobre las violaciones a los derechos humanos acaecidos durante su régimen.

La dictadura marcó fuertemente a chilenos y chilenas. En cuanto a la mujer, dice Nelly Richard (2001), su historia se debe vincular a una serie de fracturas que remecieron su identidad durante la dictadura. La mujer, explica, tuvo que transformarse en Jefe de hogar, 
toda vez que su situación familiar cambió debido al exilio y la cesantía, adquiriendo un protagonismo más fuerte dentro de la sociedad. (p. 68)

Con la transición, las mujeres obtuvieron algunos derechos. Por ejemplo, se promulgó la Ley que daba inicio al SERNAM (Servicio Nacional de la Mujer), que funciona hasta el día de hoy. Luego, el gobierno del Presidente Frei implementó un Plan de Igualdad de Oportunidades para las mujeres entre 1994 - 1999, que pretendía corregir las desigualdades de las que eran objeto. Dentro de todas las medidas, se destaca el haber diferenciado la atención de salud de la mujer del programa materno. En noviembre de 1998 la presidencia de Frei asume los acuerdos de la Convención Interamericana para prevenir, sancionar y erradicar la violencia contra la mujer, tanto en el plano público como en el privado.

Los derechos adquiridos durante la década del noventa, dicen relación con la llegada de la democracia; los movimientos sociales que se gestaron al interior del país; la participación que comenzaron a tener las mujeres en los ámbitos social y económico debido a la recesión de la década de los ochenta; los
Derechos Humanos que contemplaron el género y de los cuales se hizo partícipe el estado chileno, entre otros.

\section{Narrativa de los noventa}

La transición a la democracia fue la puerta a la libertad en cuanto a creación artística se refiere. Fue un vuelco masivo, casi inconsciente de una necesidad de plasmar en palabras la memoria. Para Carlos Orellana Riera en su artículo: "¿Nueva narrativa o narrativa chilena actual?" (Olivárez, 1997), la década del noventa fue una década de gran producción literaria. La censura y la jibarizaciónde las editoriales, durante la dictadura militar, influyó para que durante la democracia el proyecto de la editorial Planeta (Biblioteca del Sur) desbordara la creación literaria durante esta década (p.45).

El proyecto editorial de Alfaguara: Líneas aéreas, iniciado por Lenguas de trapo, intentó también abrir un espacio para la narrativa hispanoamericana. Eduardo Becerra (s.f), quien prologa la antología, piensa que además de los proyectos de las casas editoriales, también fueron importantes los premios que se establecieron por parte de éstas, como: Premios Herralde y el Premio Internacional Alfaguara (p. 16).
Es tan multitudinaria la respuesta a relatar en el Chile de los noventa y tan diversa la gama de escritores y escritoras, que ha sido difícil para la crítica aunarlos en un solo movimiento o en una sola generación, aunque algunos han hecho el intento.

De hecho, la prensa cultural denominó "Nueva Narrativa Chilena" a un grupo de escritores chilenos que publicaron en la década del noventa. En un libro homónimo, cuyo editor es Carlos Olivárez, los diferentes autores les caracterizan como escritores que rompen con el pasado inmediato, pero que son "hijos del golpe de estado"; se generan en laboratorios, es decir, en talleres literarios y son formados por escritores de renombre como: José Donoso, Antonio Skármeta o Poli Délano; poseen diversidad de estilos y un fuerte carácter individualista que rechaza todo tipo de asociación y formas de creación anterior; carecen de un propósito pragmático que los aúne; apáticos, desconfiados, ligados al éxito editorial, con un fuerte sentimiento postmodernista y en los cuales hay carencias de padres literarios.

Dentro de las integrantes de la Nueva Narrativa Chilena, está Andrea Maturana (1969) ${ }^{1}$.

1 De profesión Bióloga, Maturana se dedicó a escribir cuentos y novelas y comenzó a ser reconocida desde mediados de los ochenta, participando en antologías: Cuentos de mi país (1986), Cuentos ilustrados "Ensacados" (1987), Cuentos (1988), El cuento feminista latinoamericano (1988), Machismo se escribe con M de mamá (1989), Cuando no se puede vivir del cuento (1989)y Brevísima relación del cuento breve de Chile (1989). (Insubordinadas, Barraza, p. 175). Además, sus cuentos se incluyeron en colecciones como Pecados Capitales (1993), Cuentos con walkman (1995), 17 narradoras latinoamericanas (1996), Cuentos de invierno (1996)y Líneas aéreas (1999). Este último es la culminación de un proyecto editorial iniciado por Lengua de trapo en 1997 y que pretendía reunir a un grupo de nuevos escritores latinoamericanos (Becerra, p.13). 
Efectivamente, Maturana posee algunas características que la introducirían en la Nueva Narrativa Chilena: su formación en los talleres literarios de Pía Barros, Antonio Skármeta y Marco Antonio de la Parra; su hablar desde lo marginal femenino; trabajar en el periodismo y la televisión (Zona de contacto y Revista Ya de El Mercurio y escribir guiones para programas televisivos como Cinevideo e Historias de cine), como también la utilización que hace del espacio urbano.

El contexto sociocultural de Maturana, fue una época de mucha represión. Así afirmó Maturana en una entrevista:

... escribir en los 80 o en los 90 tenía algo más políticamente guerrero que ahora. Era un espacio que recién se abría porque había estado mucho tiempo condicionado por muchas cosas y de a poco dejaba de estar condicionado (...) La generación a la que le tocó la dictadura fue una juventud que quedó como algo “jodida”. Para nosotros eso sigue siendo un tema inevitable y esas sensaciones no creo que cambien porque se construyan más mallso edificios. No porque la ciudad sea más moderna se acaban los temas o los traumas (Barraza, s.f.).

En la narrativa de Maturana el contexto político - social se descubre entre líneas en una red de relaciones que debe ser avizorada por el lector. En el caso de los libros (Des) encuentros (des) esperados (1992), El daño (1997)y No decir (2006), por ejemplo, el tema del poder, la represión, la figura del patriarca déspota y abusador, aparece constantemente.

\section{(Des)encuentros (des) esperados}

(Des)encuentros (des)esperadoses un libro de catorce cuentos. De ellos se eligieron para el análisis: "Doble Antonia", "Roce I", "Roce II", "Roce III", "Maletas", "Piernabulario", "Cita", "Como en el teatro", "Del boceto" y "Viernes de laboratorio".

Este libro de cuentos subvierte el orden general de lo escrito hasta ahora, representa la situación de la mujer chilena de la década de los noventa, una mujer que comienza a adquirir algunos derechos y a comprenderse como un ser humano íntegro, capaz de crear, organizar, administrar, tomar decisiones en el ámbito laboral y profesional; con necesidades de todo tipo, incluso sexuales. Las mujeres son las protagonistas de estos cuentos eróticos, quienes develan sus deseos, sus soledades, y su (in)satisfacción sexual. Estos cuentos no sólo pretenden describir un acto sexual, sino más bien revelar la verdad de las sensaciones, los aciertos y fracasos, las frustraciones y esperanzas de mujeres que expresan su deseo a través de la piel, del cuerpo, de los olores, las miradas y las fantasías.

\section{La subversión del otro erótico: lo doble}

(Des) encuentros (des) esperados se articula en el constante juego de la doble significación: lo negativo, la privación, a través de los prefijos en paréntesis, pero también lo afirmativo, la abundancia. Son encuentros y desencuentros entre parejas heterosexuales en donde la mujer reafirma su ser sexual.

El juego del doble se aprecia particularmente en los personajes, aquí la mujer es el ser original y el otro (el reflejo, la sombra) es el hombre tal como aparece en el caso del otro imaginario, producido por el desvarío de Ella en "Maletas". El otro es también reflejo femenino en el desdoblamiento de personalidad de "Doble Antonia", cuando Antonia se desdobla en Helena y viceversa. Y es también el complemento de pareja erótica, otro tan humano como su original femenino.

Para Emmanuel Lévinas existe conciencia del otro como lo contrario a mí. La identificación es negación, porque significa la pretensión de que el otro sea como yo, o no exista. La conciencia del otro como distinto permite una relación intersubjetiva y recíproca, no se posee al otro, no se puede servir de él. Para Lévinas, la relación con el otro, se hace presente a través de la invocación de un rostro, el rostro aproxi- 
ma al lenguaje, que es la vía de acercamiento y verificación del otro.

La mirada es fundamental en los cuentos de Maturana para aproximarse a este otro. Es directa en "Doble Antonia" y casi voyerista, pues ella miraba el acto sexual entre Helena y su pareja cuando quedaba fuera del triángulo erótico. El juego psicológico del desdoblamiento de personalidad hace que ella se mire a sí misma, pues ella es Helena. Ella mira su espejo, lo cual tiene una doble connotación de reconocimiento de conciencia. Igualmente, Miguel nunca la mira.

"... A Helena la había conocido en calidad de misterio, en los instantes de semisueño o en la oscuridad, un poco porque le resultaba menos familiar y también porque prefería no verla..." (Maturana, 1992, p. 16).

Helena mira a Antonia, reconociéndola, respetándola, pero no sucede así con Miguel, pues él la niega al preferir a Antonia.

En "Piernabulario", la protagonista escudriña con la mirada sin temor, pues "los ojos del hombre de terno le recuerdan a otra persona"(Maturana,1992 p.55). Ella reconoce en él al otro, distinto de ella, alguien que se iguala a la mirada de la sociedad: "la otra mirada, la de ese hombre, la de la recepcionista, cada una y todas las miradas de la gente de la calle, con el mis-

mo brillo deslavado y la misma oquedad" (Maturana, 1992, p. $55,56)$.

En relación a este cuento, se ha hecho mención a un juego doble de roles por parte del amante. Un juego que lo presenta como un hombre que ante ella desarticula el sistema social y que por otro lado, se conforma como parte de él. $\mathrm{Al}$ respecto, la doctora Ángeles Mateo (2002), opina que en "Piernabulario":

\section{lo público interviene en lo privado y lo privado se hace público. Juego de aparien- cias que, en cierta manera, potencia la doble vida: la del hombre formal y casi perfecto y la del carente de "protocolo interno", el "violador del orden". Del paso del uno al otro sólo media un "terno", el disfraz del ciudadano correcto ( $p$. 201)}

No obstante, si bien abiertamente se transparenta un juego de apariencias sociales, éste no sólo está indicado por el tema de la doble vida del amante, sino que existe también un diálogo soterrado con un sistema represor:

Por debajo de la mesa te comunico que frente a mí hay un hombre vestido de terno que nos mira insistentemente, y luego aprovecho de contactar la que llamamos área cero-no mensaje y que es, además, la más erógena. Tú te das vuelta para mirar y te empalideces (...) y me agarras con demasiada fuer- za de un brazo, sacándome de allí sin darme explicaciones $(. .$.$) Otras veces he$ sentido yo también eso $(. .$. ganas injustificadas de huir (...) incluso me angustió un poco ese sujeto. Los ojos me recordaron a los de otra persona. Como si ese hombre hubiera estado siempre en los lugares que ocupamos (...) siempre ahí, al tanto de nosotros, con una mente bitácora que lo registra todo (Maturana, 1992, p. 49)

Y más adelante ella relata: "... noto que algo te molesta; el hombre de terno se te metió entre la piel y los huesos y desearía que pudieras escupirlo y olvidarte. No sé qué decir para rescatarte del miedo" (Maturana, 1992, p. 53).

Extrañamente es un hombre de terno el que los observa, traje que no sólo representa un "disfraz social", sino un signo de la CNI (Central Nacional de Investigaciones) que perseguía y detenía a todos los opositores al régimen.

Ese hombre está siempre ahí, al tanto de ellos y lo registra todo con esa mente bitácora. Las personas que vivieron en carne propia la dictadura militar chilena entienden ese signo, esa desconfianza y temor constante cuando se saben perseguidos. Lo que provoca la mirada de ese hombre en su pareja también es extraño, es incomprensible que reaccione de esa forma si se trata sólo de alguien que des- 
cubre su doble romance. Por otro lado, el metalenguaje que utilizan es similar a los códigos que se creaban en la dictadura para no ser descubiertos en sus militancias políticas, también la policía secreta utilizaba dichos códigos. Acá no sólo está referido al tema erótico al tocar su pene. El área cero, es la del no mensaje: guardar silencio, no hablar frente al peligro y es este código que utiliza ella cuando aparece el hombre de terno.

Sin duda hay referencia a un distanciamiento de su pareja porque no es parte de los que están en contradicción con el sistema social, pero también da luces de que ese sistema es también político, haciendo presente un diálogo con una reciente memoria histórica.

Por otro lado, ambos intentan escapar de las miradas de los demás a través del código gestual que realizaban por debajo de la mesa. La mirada es fundamental para la conexión espiritual y amorosa con el otro amante.

En "Como en el teatro", todos los otros miran a la pareja, incluida la narradora también como una especie de voyerismo. "El mozo, el barman y los clientes de más de una mesa mantuvieron los ojos fijos en su abrazo, en sus pasos torpes y a tropiezos, en ese beso casi caníbal que se dieron en el alero de la puerta." (Maturana,
1992, p. 77). El mirar de esos otros los distancia de ellos y los encuentra como pareja. Las miradas entre la pareja que se cita en "Roce II" son el código para constatar que nunca su encuentro amatorio puede consumarse, separándose por temor al saber que su relación será única, de un amor incontenible. En "Roce I y III", al igual que en "Doble Antonia", él no la mira, porque no le interesa o porque la posición se lo impide. Sólo que en "Roce III", es porque ella decide no hacerlo, ella no se voltea, al igual que en "Cita". En este cuento, ella se aprecia en el espejo y le gusta verse así, "con las pupilas más dilatadas y los labios engrosados y oscuros, humedecidos por su propio aliento." (Maturana, 1992, p.66). En "Maletas" ella tampoco lo mira. "No lo miré; nunca he podido hacerlo" (Maturana, 1992, p. 43). La negación de la mirada indica posesión y quien tiene el poder del otro en todas escenas eróticas son mayoritariamente los personajes femeninos. La mirada la otorgan o la niegan las protagonistas en los cuentos analizados y se condice con el desencuentro o el encuentro erótico.

\section{Voz narrativa}

En la mayoría de los cuentos analizados de (Des)encuentros (des)esperados, la voz que relata es de una narradora homodiegética femenina. Esto se puede apreciar en: "Roce III", "Maletas", "Piernabulario", "Como en el teatro", "Del boceto", "Viernes de laboratorio". El resto de los cuentos (4), se relatan en tercera persona con narradores heterodiegéticos.

Las narradoras homodiegéticas dialogan en distintos tiempos: desde una visión hegemónica de sexualidad, pero también desde una subversión hacia ésta. Son narradoras que utilizan un lenguaje simbólico - persuasivo, profanando el hermetismo que se tenía del deseo femenino. Así, por ejemplo, en "Roce III", la narradora relata el acoso de un hombre cualquiera en un ascensor. El hombre instaura su poder, pretende dominarla a través de las palabras. Sin embargo ella, sabiéndose amenazada, nunca quiere mirarlo, porque sabe que no puede recordar a alguien que no huele a nada (Maturana, 1992, p. 39). Al final de la historia, ella le responde que su nombre es Eugenia, al igual que la mujer que lo dejó, manteniendo así una distancia y haciendo casi una burla de su relato.

Por otro lado, la narradora de "Maletas" es una mujer traicionada por una larga historia de promesas rotas y mentiras, pero que logra superar sus miedos, crecer, dejarlo partir espiritualmente y lo hace a través de una masturbación. En este cuento la imagen fic- 
ticia del otro (varón) que regresa, adquiere poder frente a ella, la intimida con su recuerdo porque "lograba acariciarle hasta los huesos" (Maturana, 1992, p. 44). Ella siente temor: "abrí los ojos con miedo, el mismo que no he dejado de sentir desde que se fue" (Maturana, 1992, p. 44), sin embargo es capaz de despertar de esa ensoñación y cuando lo hace, lo hace debido al orgasmo que se había auto provocado.

En "Piernabulario" la narradora personaje es una mujer de menor edad que su amante y sin embargo, desde esa condición etaria y de ser mujer (supuestamente sin logos), logra realizar asociaciones para descubrir el conflicto de su pareja. Se da cuenta que le miente, que "por encima de su ropa informal se dibuja a la perfección un terno igual al del hombre de terno café..." (Maturana, 1992, p. 55 y 56.)

La narradora de "Como en el teatro" es una mujer con cáncer en el seno que decide evadir su problema de salud, yendo a un café para observar la vida de otras personas, siendo testigo de un amor apasionado. Ella se aleja del lugar por un tiempo, debido a su operación y cuando regresa se encuentra con una pareja distinta (él con su esposa), una pareja vacía, que no se mira con ternura, ni se toca. Ella se distancia como narradora, la extirpación del órgano femenino sirve para eso, para sentirse más racional.
En el cuento "Del boceto" la narradora es Tatiana, un ente inventado por Nicolás, un arquitecto cansado de tener relaciones vacías. Tatiana nos relata que él la inventó con formas extrañas con tal de no amarla y creó toda una trama para una relación, con final incluido y las ganas de él de su regreso, como si fuera un ser verdadero, existente. Tatiana, nos cuenta cómo ella, con el paso de la historia se va haciendo real y llega a la puerta de Nicolás simplemente a decir: "Hola, Nicolás. Ya volví" (Maturana, 1992, p. 97). Se intertextualiza en este cuento la creación mítica, la creación de la mujer a partir del hombre. Sólo que nuevamente encontramos una subversión, pues "la" ser creada se hace realidad por ella misma y adquiere tal poder, que Nicolás deja de vivir tranquilo pensando en ella, se masturba pensando en ella y tiene pesadillas con ella, ella se hace imprescindible para él.

"Viernes en laboratorio" es una carta de contestación. El relato de la narradora es a través de su propia misiva destinada a un hombre del cual estuvo enamorada. Ella es una mujer despechada por esa relación inconclusa que siempre tuvo final. Nos relata el acto sexual mantenido con el destinatario de la carta en un diminuto laboratorio fotográfico, sus sentimientos y la partida de él; todo esto como una larga introducción para dar respuesta acerca de unos papeles de revelado muy difíciles de conseguir en el país donde él habita. Al final de la carta nos enteramos que ella los había velado a propósito, porque supo desde el principio que ésa iba a ser la única vez en que él la iba a amar:

... te mentí acerca de las
cajas que dejé abiertas para
poder escribirte alguna vez,
como ahora, y decirte que
esos papeles, los inconse-
guibles, terminaron velados
a fuerza de luz y son ahora
tan inservibles como los re-
cuerdos de ese viernes. (Ma-
turana, 1992, p. 111).

En este cuento se perfila otro juego de metáforas y poderes, pues si bien el control lo tenía él en el acto sexual, finalmente lo posee ella al "dar luz". La luz es símbolo de conocimiento, propio del logos masculino, no obstante en este relato, quien lo utiliza es la mujer - narradora. Al dar luz a los papeles de revelado y destruirlos, también "da luz" a su intervención en el conocimiento de esa relación frustrada, una relación que él nunca concibió como tal.

Por otro lado, el género epistolar con el cual dialoga la narradora, la distancia de los acontecimientos. Así mismo, la carta no posee destinatario, fecha, lugar ni firma. El vacío del anonimato y el distanciamiento de los hechos nos da cuenta de que es algo que cualquier mujer puede hacer, en cualquier espacio y tiempo. En consecuencia, nuevamente se 
aprecia aquí una apropiación del logos (masculino) por parte de la narradora.

\section{Los personajes}

La mayoría de los personajes son seres innominados, a excepción de "Doble Antonia", "Roce I", "Del boceto" y "Cita" (en que figura el nombre de él: Esteban, pero según la narradora era "un nombre que no podía ser verdadero" (Maturana, 1992, p. 62).

Las protagonistas en su mayoría son mujeres que logran (o por lo menos intentan) profanar/liberar quejidos a través del cuerpo. El cuerpo es un cuerpo comunicante, no sólo de su libido y emociones, sino como un todo completo, capaz de expresar su condición de seres racionales.

En estos cuentos se dialoga con esa condición de "ser" mujer, no de oponerse al otro (varón), éste es percibido como pareja, en una relación de iguales con ella.Ciertamente es Ella la protagonista, pero siempre está o aparece este Otro como ayudante del personaje, como compañero de una relación que no pudo darse o se dio. Miguel, Rodrigo, el supuesto Esteban, Nicolás y los Él de los otros cuentos, no son seres detestados por Ellas, en el peor de los casos, son hombres que fueron objeto para su aprendizaje ("Maletas" y "Viernes de laboratorio").
Su pene erecto tampoco les da poder, ni se decodifica en sus acciones el rótulo social de "potencias sexuales". De hecho, las mujeres toman la iniciativa en asuntos eróticos. No son entes pasivos, son ellas en estos cuentos quienes provocan placer, ("Doble Antonia" y "Piernabulario"); quienes se auto provocan placer ("Maletas" y "Cita"); quienes lo rechazan ("Roce I", "Roce II" y "Roce III") o quienes lo aceptan ("Del boceto" y "Viernes de laboratorio"). Esto se puede percibir a través del análisis de algunas acciones que ejecutan.

En "Doble Antonia", por ejemplo, Antonia es quien provoca a Miguel:

... había acercado los labios al lóbulo de su oreja, cuidando que su pezón rozara, le había musitado tibiamente, lo había lamido hasta el cansancio entero, lo había acariciado bajo la ducha, jugaba con su tetilla, elevándola con los dedos y mojándola con la lengua. Cuando él dormía, no dejaba de acariciarlo, sin mover los labios de su pecho. Helena lo sostenía con precisión, le lamía los labios, lo tomaba sin piedad, lo cabalgaba, le maullaba en su oído, le enterraba las uñas en la espalda, le mordisqueaba el cuello, le producía orgasmos (Maturana, 1992., pp. 12 a 18).

Un análisis lingüístico prueba que los personajes femeninos realizan acciones eróticas propias del sujeto activo (varón), según la "norma" social. Ellas realizan acciones eróticas reiterativas como: entreabrir, sostener, tomar, cabalgar, arrastrar, querer, inventar, proteger, empapar, abrir, tender, controlar, reconstruir, humedecer, no cesar, verter, agotarlo, lamer, enfrentar.

El lenguaje de (Des)encuentros (des)esperados en materia erótica, es provocador, impúdico para una década recién salida a la libertad. Los sustantivos: pechos, pezón, piernas, ombligo, vientre, son palabras perturbadoras para la moral de la época. También los son las acciones eróticas realizadas por los personajes femeninos y todavía más la descripción eufemística de los orgasmos femeninos: "...un extraño elixir que vierte sobre el encaje (...) hasta que por fin sube, los ojos fijos, gime, el cuerpo tenso, respira, se curva, lame los dedos húmedos, se contrae, se eleva. Muere. (Maturana, 1992, p. 65.)

\section{Los espacios físicos del erotismo}

Las atmósferas en donde se desarrolla la historia también tienen que ver con lo anterior. Maturana sitúa a sus personajes femeninos en la calle, en un ascensor de un edificio de altura (idea fálica, si se quiere), en un metro, en un laboratorio fotográfico, en los cafés, en los moteles, etc., espacios sociales determinados para el varón, espacios públicos, de trabajo, del afuera. Situación 
que se da primordialmente en los cuentos de "Roce I, II y III", "Piernabulario", "Cita" y "Como en el teatro".

Subversión espacial que se condice nuevamente con el poder que adquiere la mujer. Según Guerra(2006):

\begin{abstract}
Las relaciones entre hombre y mujer están signadas, en primera instancia, por una dicotomía de territorios: mientras el hombre, en su posición de Sujeto, tiene acceso al mundo del afuera y a la movilidad ontológica de la trascendencia, la mujer en la casa es el margen subordinado, la pasiva inmanencia. (p. 139).
\end{abstract}

En estos cuentos, en cambio, se presenta una visión de mundo en que los personajes femeninos utilizan los mismos dominios para el erotismo que los personajes masculinos.

Los espacios de estos cuentos son ciudades modernas, por lo general innominadas e inespecíficas. La primera línea del cuento "Roce I" comienza con la expresión: "Nadia camina cansada por la calle", ella se traslada, lo ha hecho por bastante tiempo, es un ente trashumante, al igual que Rodrigo "entre millones de personas de gesto indistinguible" (Maturana, 1992, p. 22). Los detalles que se dan del espacio en "Roce II" son escasos, existen postes de alumbrado, calles, una esquina. Él se traslada en micro y ella en auto para encontrarse en esa esquina. La esquina direc- ciona para dos lugares distintos, representa la disyuntiva en la que se encuentra la pareja de futuros amantes para continuar con su cita y su relación, pero finalmente: "no hay coordenadas geográficas o temporales que los sostengan" (p. 29). "Roce III" posee un espacio cerrado, pero ella "odia cualquier cosa encerrada de la que no se baje a voluntad" (Maturana, 1992, p. 35). Es un espacio público, el ascensor de un edificio donde trabajan muchas personas. Ella se dirige al piso 9, sin embargo esta vez no alcanza a llegar, ya que el ascensor es intervenido por él al detenerlo en emergencia. Él le impide moverse para hacerla su confidente, pero no lo hace con brusquedad ni violencia. Su afán es sólo que lo escuche.

Los cuentos: "Como en el teatro" y "Piernabulario" ocurren en cafés, bares o restaurantes, lugares también públicos. El espectro se amplía y nomina abiertamente en "Piernabulario", se mencionan el estadio, un bar en Patronato, las calles: Copiapó, Cienfuegos, Rosas, Cumming y se habla expresamente de Santiago. Ellos transitan por estas calles en busca de un motel. Los espacios son cómplices para que su relación no prospere. "Es una ciudad de mierda con cien micros por cuadra, con hoteluchos sin personalidad, con paredes descascaradas tras el terremoto, colchones con hoyos negros". También se mencionan los espacios abiertos como el Arra- yán, lugar que una vez visitaron y la Plaza Brasil, el lugar donde ella establece las conjeturas del silencio de él.

La protagonista de "Como en el teatro" escoge un barrestaurant para no estar sola. "Quería adueñarse de un espacio que le perteneciera" (Maturana, 1992, p. 71). El lugar era cercano a su domicilio, pequeño, íntimo, no iba cualquier tipo de gente. También se menciona ligeramente el hospital donde ella asiste para ser operada de cáncer. El bar representa el escenario de la obra donde ella es espectadora de todos los detalles de una relación. "Si hubiera sido cine, se habría congelado la imagen en escena, la escena de una familia feliz" (Maturana, 1992, p. 80).

"Cita" se desarrolla en un vagón del metro atestado de gente, espacio cerrado pero también público. Después del encuentro, ella baja del metro para buscar el motel indicado por el hombre que tocó su piel intacta, cárcel intacta (metáfora de virginidad). Sin embargo, él no llega y esto no fue obstáculo para saciar su deseo. En el dormitorio del motel sobresale el color rojo, signo del deseo y pasión. El rojo ambienta el espacio para que la mujer obtenga su placer erótico: “... todo se iluminó de rojo, envolviéndola en un calor nuevo, en una intimidad que la golpeaba desde todos los rincones de la habitación y se multiplicaba en cada uno de los espejos ubicados es- 
tratégicamente alrededor de la cama." (Maturana, 1992, p. 64).

Finalmente, las historias que se desarrollan en espacios cerrados son alcobas, casas y departamentos. Llama la atención que los objetos que circundan el espacio como: el sofá, la alfombra, se ensucian con la presencia (ficticia) de él y sus promesas en "Maletas". En el caso de "Viernes de laboratorio", la historia transcurre en el laboratorio fotográfico de ella, un espacio muy pequeño, estrecho, sucio, con rincones repletos de chanchos de tierra y ciempiés, de baldosas frías, con una gran luz roja. La mezcla de lo natural con lo artificial en este cuento, presenta también este doble juego en el espacio. Es el espacio de ella, no simplemente por ser propietaria, sino por los elementos que lo contienen: emoción y logos, naturaleza y ciudad, lo de afuera y lo de adentro; esto la faculta para tomar la decisión de mentirle con respecto al papel fotográfico y decidir acerca de esta relación.

\section{Consideraciones finales}

El erotismo es el deseo sexual que se concreta en un acto sexual real o ficticio. No tiene fines reproductivos y es esencialmente amoroso, pues la persona deseada siente un grado de amor hacia el/la otro/a amante. Es el placer que se obtiene con este otro/a amado/a. En los cuentos analizados de (Des)encuentros (des)esperados todas las relaciones sexuales que se mencionan, ya sea de los personajes protagónicos o secundarios, no tienen un afán reproductivo, pero sí la búsqueda de un complemento que les lleve a amar y a completar el vacío existencial en que se encuentran. Es una búsqueda notoriamente ansiada y necesaria.

Como ya se ha probado en el análisis, en este texto literario se revierte el prototipo sexual asignado para la mujer en el acto sexual. Definitivamente los personajes femeninos de (Des) encuentros (des)esperados son personajes que toman decisiones, crean juegos sexuales, participan de ellos, son seres activos en cuanto a sus deseos. Las mujeres de los cuentos ya no se comportan como el ser pasivo y dominado en el acto sexual, pues en más de una ocasión ellas lo hacen y muchas veces se percibe que la pareja está colu- dida para provocarse deseo en conjunto. Ellas utilizan espacios públicos para amarse (bares, restaurantes), asisten solas a un motel ("Cita"), situaciones impensadas de ser desarrolladas por mujeres, de acuerdo a lo presentado en literatura hasta la década anterior.

Claramente, en este texto se observa un reconocimiento del cuerpo femenino como un efecto de extrañamiento, algo que se descubre y se desnuda fuera de la alcoba, ocupando espacios inimaginables que llaman a la sensualidad. Existe un reconocimiento de sus zonas erógenas, que muchas veces son acariciadas por la misma mujer para satisfacer su deseo sexual, demostrando que ésta tiene apetitos sexuales, al igual que el hombre.

El lenguaje utilizado para hablar de esto, es un lenguaje que no vilipendia ni mancilla lo erótico, por el contrario, lo regresa al pedestal en que alguna vez estuvo, cuando el acto sexual se conformaba como un rito sagrado, de comunicación sublime entre dos cuerpos. 


\section{Referencias}

\section{A. Libros:}

Foucault, Michel. (1992). Historia de la sexualidad. Volumen III: La inquietud de sí, Madrid, España: Siglo veintiuno editores.

Foucault, Michel. (1993a). Historia de la sexualidad. Volumen I: La voluntad de saber, Madrid, España: Siglo veintiuno editores, Madrid, 1993

Foucault, Michel. (1993b). Historia de la Sexualidad. Volumen II: El uso de los placeres, Madrid, España: Siglo XXI editores.

Freud, Sigmund. (1954). Pulsión y destino de pulsión. En Obras Completas. Ed. Amorrortu, p. 175.

Genette, Gérard. (1989). Figuras III. “Discurso del relato”, Barcelona, España: Lumen, p. 75 -327.

Guerra, Lucía. (2006). La mujer fragmentada: Historias de un signo, Santiago, Chile: Editorial Cuarto Propio.

Lévinas, Emmanuel. (1987). De otro modo que ser, o más allá de la esencia. Salamanca, España: Sígueme.

Maturana, Andrea. (1992). (Des)encuentros (des)esperados, Santiago, Chile: Alfaguara.

Olivárez, Carlos. (1997). Nueva narrativa chilena. Colección texto sobre texto, Santiago, Chile: Editorial LOM. Artículos: Orellana Riera, Carlos. ¿Nueva narrativa o narrativa chilena actual?, Olea, Raquel. La niña sudaca irá a la venta.

Paz, Octavio. (1993). La llama doble. Amor y erotismo. Barcelona, España: Seix Barral S.A.

\section{B. Documentos electrónicos:}

Aristóteles. (2007). La política. Recuperado el 20 de agosto de 2010, de http://www.laeditorialvirtual.com. ar/Pages/Aristoteles_LaPolitica/Aristoteles_LaPolitica_000.htm

(Barraza, Vania. (2007). La palabra tiene algo de magia negra y blanca: entrevista a Andrea Maturana. Revista Grafemas: Boletín electrónico de la AILCFH.

Recuperado el 12 agosto 2010, de http://www.panam.edu/dept/modlang/grafemas/febrero_07/barraza. html

Rousseau, J.J. (1762). Emilio o la Educación. Ed. Recuperado el 10 de diciembre de 2010 de: http://escritoriodocentes.educ.ar/datos/recursos/libros/emilio.pdf

Diccionario de la Real Academia Española. Recuperado el 17 de noviembre de 2010, de: http:/ /buscon.rae. es/draeI/SrvltConsulta?TIPO_BUS=3\&LEMA=erotismo.

Dictionary of Greek and Roman Biography and Mythology.Recuperado el 20 de noviembre de: http:// www.theoi.com/Ouranios/Eros.html/ 
Richard, Nelly. (2001). Residuos y metáforas. Ensayos de crítica cultural sobre el Chile de la transición. Recuperado el 15 de diciembre de 2010 de www.clacso.or.ar/bibliotecavirtual

\section{Documento de internet sin fecha}

Bataille, Georges (s.f.). El erotismo. ScanSpartakku - Revisión:TiagOff. Recuperado el 7 de noviembre de 2010, de: http://www.mocpy.org/polosur/images/stories/libros/El\%20Erotismo-\%20georges\%20 bataille.pdf

Becerra, Eduardo (s.f.). Momento actual de la narrativa hispanoamericana: otras voces, otros ámbitos.

\section{Base de datos de la Doctora Vania Barraza, TheUniversity of Memphis:}

Crosby, Margaret. La traición paterna y el incesto en El daño de Andrea Maturana. Chen Sham, Jorge; Chiu-Olivares, M. Isela (s.f.).Periódico De márgenes y adiciones; novelistas latinoamericanas de los 90. San José de Costa Rica, Ediciones Perro A. Artículo de Pág. 237 -258.

Maíz-Peña, Magdalena. (2002). "Los apetitos de la ansiedad: cuerpo-texto de Andrea Maturana", Vol. 5, Num.10, Enero a Junio de 2002, págs. 179-186.

Mateo del Pino, Ángeles. (2002). Cuando lo que (des) une no es el amor sino el espanto (El discurso de la modernidad en la narrativa chilena actual: Andrea Maturana. Volumen 5, Num. 10, fecha Enero a Junio de 2002, págs. 187- 202.

Villalobos, Daniel (s.f.). “(Des)encuentro (des)esperados” de Andrea Maturana. La ciudad de vigila. En Reflexiones, ensayos sobre escritoras hispanoamericanas contemporáneas. 